TORRES, A.C.; DUVAL, F.G.; RIBEIRO, D.G.; BARROS, A.F.F.; ARAGÃO, F.A.D. Efeito da sacarose, cinetina, isopentenil adenina e zeatina no desenvolvimento de embriões de Heliconia rostrata in vitro. Horticultura Brasileira, Brasília, v.23, n.3, p.789-792, jul-set 2005.

\title{
Efeito da sacarose, cinetina, isopentenil adenina e zeatina no desenvolvi- mento de embriões de Heliconia rostrata in vitro
} Antonio Carlos Torres'; Fernanda D. Duval2; Dalva G. Ribeiro²; Ana Flavia F. Barros ${ }^{1}$; Fernando A.D. Aragão ${ }^{1}$
Embrapa Hortaliças, C. Postal 218, 70359-970 Brasilia-DF; E-mail: torres@ @nph.embrapa.br; ${ }^{2}$ UnB, Dept. Botânica, c.p. 04457 70919-970 Brasilia-DF

\section{RESUMO}

Embriões provenientes de frutos maturos de Heliconia rostrata Ruiz \& Pavon foram excisados e inoculados em meio de cultura contendo os sais básicos MS, vitaminas e sacarose. A adição de sacarose foi essencial para o desenvolvimento dos embriões. Em meio desprovido de sacarose os embriões morreram em cultura. Concentrações de $1 \%, 2 \%$ e $3 \%(\mathrm{p} / \mathrm{v})$ de sacarose favoreceram o desenvolvimento dos embriões. Concentrações de 6\%, $9 \%$ e $12 \%$ $(\mathrm{p} / \mathrm{v})$ de sacarose inibiram o crescimento dos embriões. A adição de cinetina, isopentenil adenina e zeatina não favoreceram o crescimento e o desenvolvimento dos embriões.

Palavras-chave: cultura de embriões, micropropagação, cultura de tecidos.

\begin{abstract}
Effect of sucrose, kinetin, isopentenyl adenine and zeatin on the development of embryos of Heliconia rostrata in vitro

Embryos from mature fruits of Heliconia rostrata were excised and cultured in basal medium containing MS salts, vitamins and sucrose. Sucrose was essential for embryo development. In meclium without sucrose the embryos died in culture. Sucrose concentrations of $1 \%, 2 \%$ and $3 \%(\mathrm{w} / \mathrm{v})$ were beneficial for embryo development. Sucrose concentrations of $6 \%, 9 \%$ and $12 \%(w / v)$ inhibited embryo growth. The addition of kinetin, isopentenyl adenine and zeatin did not improve embryo growth and development.
\end{abstract}

Keywords: embryo culture, micropropagation, tissue culture.

(Recebido para publicação em 28 de julho de 2004 e aceito em 18 de abril de 2005)

\begin{abstract}
A s helicônias são plantas monocotiledôneas, pertencentes à família Heliconiaceae, que apresenta de 200 a 250 espécies (BERRY; KRESS, 1991). Sua aceitação como flor de corte tem sido crescente nos mercados nacionais e internacionais pela beleza de suas inflorescências, de intenso colorido, algumas vezes com tonalidades contrastantes e com longo período póscolheita (CASTRO, 1995).

Normalmente, a propagação comercial das helicônias se dá por via assexuada, pela divisão do rizoma (CRILEY, 1988; CASTRO, 1995). Esse método conduz à disseminação e acúmulo de agentes causais de importantes doenças que são transmitidas entre plantios sucessivos, via rizomas contaminados. Dentre essas doenças estão as causadas por fungos de solo.
\end{abstract}

Em várias espécies de plantas a falha de se obter sucesso na propagação sexuada é devido ao abortamento dos embriões. Embora ocorra polinização e fertilização, as sementes podem conter embriões não desenvolvidos ou pouco desenvolvidos que não germinam. Outras vezes, devido à dureza do endocarpo os embriões não conseguem germinar. Em helicônia, o fruto apresenta um endocarpo duro que dificulta a germinação das sementes (CASTRO, 1995; SIMÃO; SCATENA, 2003). A cultura de embriões tem sido usada para recuperar genótipos em situações onde ocorre falha no desenvolvimento da semente ou impedimento da germinação (RAPPAPORT, 1954; NARAYANASWAMI; NORTOG, 1964; HU; FERREIRA, 1998).

A utilização da técnica de resgate de embriões da helicônia propicia a propagação rápida de plantas, a recuperação de plantas livres de doenças, a conservação e intercâmbio de germoplasma, a introdução de germoplasma como semente botânica, a avaliação de aspectos nutricionais e fisiológicos do desenvolvimento do embrião e a superação da dormência de sementes.

\section{MATERIAL E MÉTODOS}

O presente trabalho foi realizado no laboratório de Biologia Celular da Embrapa Hortaliças. O material vegetal utilizado foi proveniente da plantação de helicônia do Rancho Paraná, localizado em Brazlândia (DF). Sementes de Heliconia rostrata foram retiradas de frutos maduros, com coloração azul-escura. O pericarpo foi removido e os embriões (no estádio cotiledonar), foram excisados por uma leve pressão nas sementes, com o auxílio de uma pinça (Figura 1) e colocados em uma placa de Petri, contendo papel umedecido com água destilada. Os embriões foram desinfestados com solução de hipoclorito de sódio a $0,5 \%(\mathrm{v} / \mathrm{v})$, durante 15 minutos e, em seguida, lavados três vezes com água destilada autoclavada.

Em uma capela de fluxo laminar os embriões foram inoculados em frascos de $250 \mathrm{ml}$ de capacidade, com $40 \mathrm{ml}$ de meio nutritivo básico, contendo sais minerais MS (MURASHIGE; SKOOG, 1962) e, em mg L'-1: i-inositol 100; tiamina- $\mathrm{HCl} 1,0$; piridoxina- $\mathrm{HCl} 0,05$; ácido nicotínico 0,05 ; glicina 2,0; e Phytagar (Sigma) 7.000. Ao meio foram adicionadas, respectivamente, concentrações de: 1$)$ Sacarose $(0 ; 1 ; 2 ; 3 ; 6 ; 9$ e $12 \%$ p/v) sem adição de reguladores de crescimento; 2) Cinetina ( $0 ; 0,5 ; 1,0 ; 2,0$ e $\left.3,0 \mathrm{mg} \mathrm{L}^{-1}\right)$; 3) Isopentenil adenina ( 0 ; 0,$5 ; 1,0 ; 2,0$ e $\left.\left.3,0 \mathrm{mg} \mathrm{L}^{-1}\right) ; 4\right)$ Zeatina $\left(0 ; 0,5 ; 1,0 ; 2,0\right.$ e $\left.3,0 \mathrm{mg} \mathrm{L}^{-1}\right)$.

Nos meios contendo regulador de crescimento (items 2, 3 e 4), a concentração de sacarose foi de $3 \%(\mathrm{p} /$ 


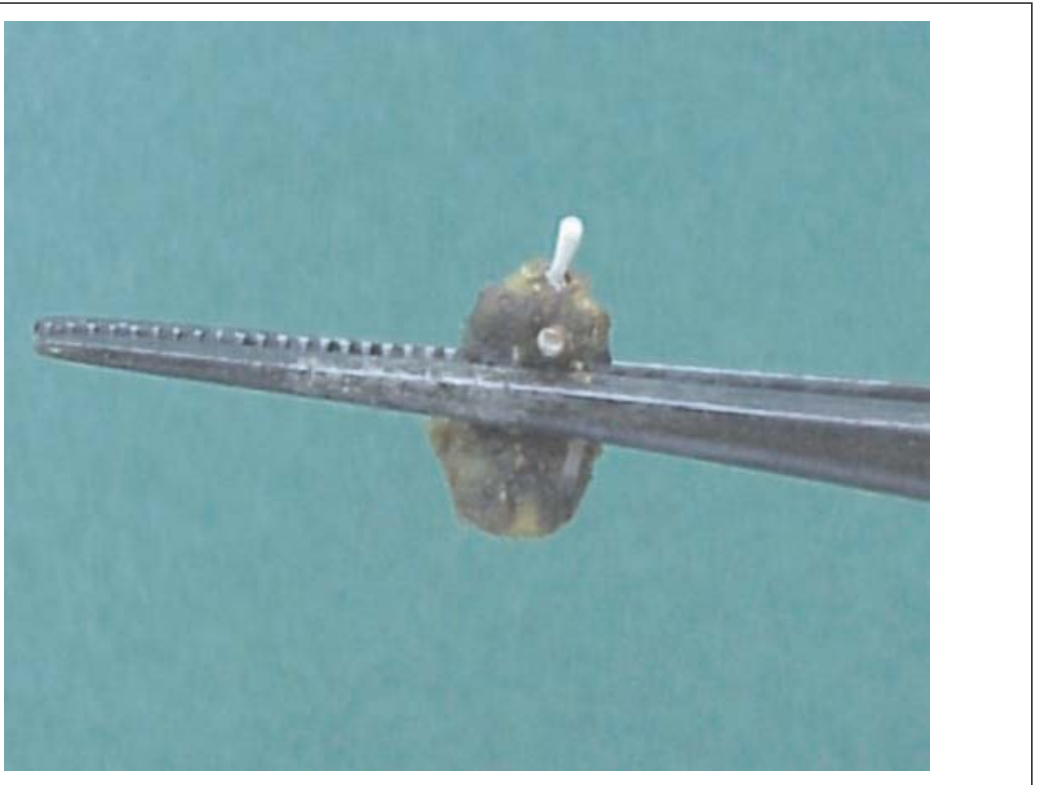

Figura 1. Embrião de H. rostrata sendo excisado da semente com o auxílio de uma pinça. (o tamanho da semente da foto é de 1,0 cm). Brasília, Embrapa Hortaliças, 2004.

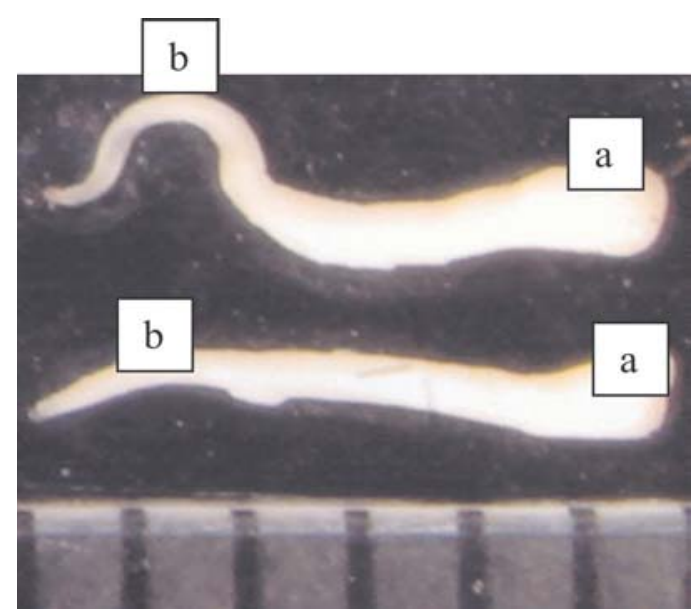

Figura 2. Embriões de Heliconia rostrata mostrando bainha cotiledonar (a) e haustório (b). (cada divisão da régua da figura corresponde a 1 mm). Brasília, Embrapa Hortaliças, 2004.

v). As culturas foram mantidas a $27^{\circ} \mathrm{C}$ e iluminadas com lâmpadas fluorescentes, com fotoperíodo 16 horas e densidade de fluxo luminoso de 32 $\mu \mathrm{mol} \mathrm{m} \mathrm{m}^{-2} \mathrm{~s}^{-1}$.

$\mathrm{O}$ delineamento experimental foi inteiramente casualizado, com 10 repetições. Cada parcela consistiu de um frasco com cinco embriões. Foram avaliados: (1) percentagem de plântulas formadas, (2) massa fresca e (3) comprimento das plântulas. Os dados foram coletados entre 40 a 60 dias de cultura. Foi realizada uma análise de variância e regressão para a percentagem de plântulas formadas em função das diferentes concentrações de sacarose e dos efeitos dos reguladores de crescimento, considerando-se significativo quando os valores de $\mathrm{P}$ (probabilidade do teste aplicado) foram abaixo de $5 \%$. O teste de Tukey foi utilizado para distinção das médias estimadas. Todas as análises foram realizadas no software computacional MSTATC (Version 2.10, Michigan State University, MI). As plantas obtidas foram transplantadas para vaso contendo mistura de areia e vermiculita $1: 1(\mathrm{v} / \mathrm{v})$ e mantidas em casa de vegetação.

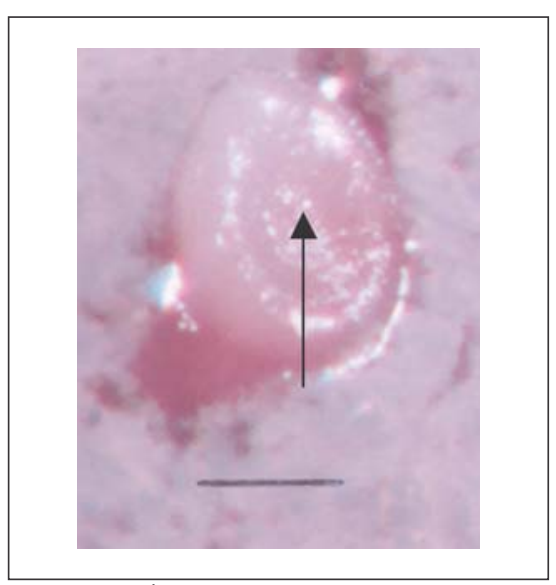

Figura 3. Ápice caulinar do embrião de $H$. rostrata após a remoção da bainha cotiledonar e haustório. Letra (a) protófilo. Seta: meristema apical caulinar. Barra $=125$

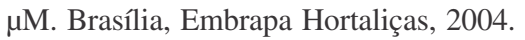

\section{RESULTADOS E DISCUSSÂO}

Estudos preliminares mostraram que a germinação de sementes de $H$. rostrata, em areia umedecida é baixa (em torno de $4 \%$ ), tornando ineficiente a propagação dessa espécie por via sexuada. Vários autores relatam que o embrião de helicônia está pouco desenvolvido (CRILEY, 1986, citado por CASTRO, 1995; STILES, 1979, citado por CRILEY, 1988), pouco diferenciado (GATIN, 1908, citado por CRILEY; BROSCHAT, 1992) ou rudimentar (CRILEY, 1995) na época de maturação dos frutos. A combinação de um embrião rudimentar com o endocarpo duro acarreta em uma germinação esporádica e demorada (CRILEY, 1988). Entretanto, essas observações sobre o desenvolvimento do embrião não se aplicam para $H$. rostrata, cujo embrião utilizado como explante apresenta-se envolto por uma bainha cotiledonar dilatada, de coloração creme-clara, que se prolonga em um haustório tubular, reto ou com a porção distal curvada, de coloração branca, com comprimento variando entre 4 e $6 \mathrm{~mm}$ (Figura 2). Na Figura 3 pode ser visualizado o embrião no estádio cotiledonar de desenvolvimento após a remoção da bainha cotiledonar e do haustório. Esse embrião não apresenta dormência quando cultivado in vitro em meio adequado.

A adição de sacarose ao meio básico foi essencial para o desenvolvimen- 
to dos embriões in vitro, ao contrário do meio desprovido de sacarose, onde não houve o crescimento dos embriões. Aos 40 dias de cultivo esses embriões apresentaram coloração marrom-claro característica da degeneração em cultura. A necessidade de adição de sacarose no meio para cultura de embriões tem sido observada por vários autores, em distintas espécies de plantas (RIETSEMA et al., 1953; RAGHAVAN; TORREY, 1963; HU; FEREIRA, 1998), principalmente em cultura de embriões em estádios iniciais de desenvolvimento (próembriões). Nas células, carboidratos são necessários como fonte de energia e de carbono nos processos biossintéticos (GÖSSLOVÁ et al., 2001) e servindo também, como agentes osmóticos (TREMBLAY; TREMBLAY, 1991). Neste trabalho foi observado que, em meio suplementado com sacarose, nas concentrações de $1 \%, 2 \%$ e $3 \%$ houve crescimento e desenvolvimento da parte aérea e de raízes adventícias em forma de rosetas na porção basilar. Não foi observada a presença de raiz principal. Quando a concentração de sacarose foi aumentada para $6 \%$, a percentagem de plântulas formadas foi reduzida para $5,9 \%$ e, por conseqüência, essas plantas apresentaram coloração roxa-clara. Concentrações maiores de sacarose no meio (9\% e 12\%) inibiram a germinação dos embriões, possivelmente devido a queda do potencial osmótico do meio. Trabalho ilustrativo da importância da osmolaridade do meio sobre o crescimento dos embriões de Datura stramonium foi feito por Rietsema et al. (1953). Nesse estudo, embriões maturos de $D$. stramonium desenvolveram-se em meio desprovido de sacarose, enquanto embriões em estádios precoces exigiram, progressivamente, alta concentração de sacarose. Para $H$. rostrata a concentração de $3 \%$ de sacarose foi empregada nos trabalhos subseqüentes de otimização de meio de cultura.

A análise de variância da regressão do percentual de plântulas produzidas em função da concentração de sacarose no meio foi significativa a $5 \%$ de probabilidade. O coeficiente de determinação $\left(\mathrm{R}^{2}\right)$ foi alto $(0,79)$, indicando que a curva estimada apresenta uma grande associação com os dados observados (Figura 4). A curva estimada foi: $y=0,68 x^{3}-13,11 x^{2}+60,58 x$.

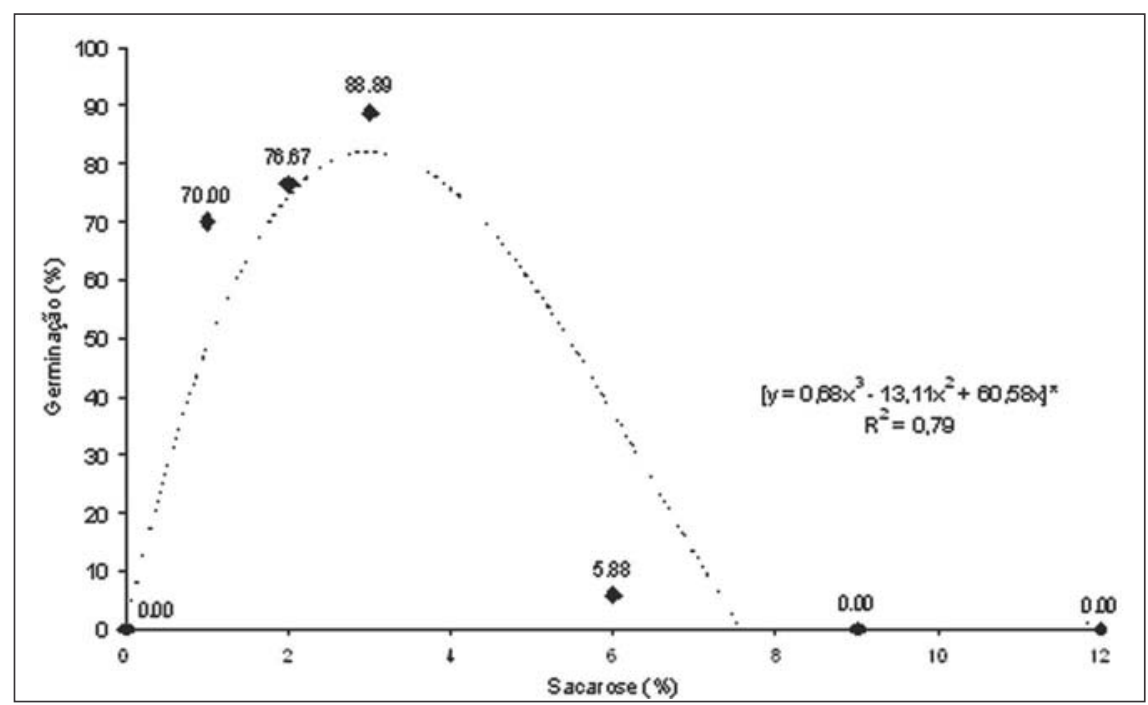

Figura 4. Análise de regressão para percentagem de plântulas formadas desenvolvendo em meio de cultura contendo os sais básicos MS, vitaminas e sacarose. Brasília, Embrapa Hortaliças, 2004.

* análise da regressão polinomial, significativa a 5\%.

Tabela 1. Médias de comprimento, \% de plântulas formadas e massa fresca de plântulas $H$. rostrata em função de concentrações de, respectivamente, cinetina, Isopenteniladenina e zeatina, no meio de cultivo. Dados coletados após 54 dias de cultura. Brasília, Embrapa Hortaliças, 2004.

\begin{tabular}{|c|c|c|c|}
\hline Citocinina (mg L-1) & \% de plântulas & Massa fresca $(\mathrm{g})$ & Comprimento (cm) \\
\hline \multicolumn{4}{|l|}{ Cinetina } \\
\hline 0 & 1,4474 NS & 0,1538 NS & 2,2222 NS \\
\hline 0,5 & $1,4318 \mathrm{NS}$ & $0,0986 \quad N S$ & $1,7250 \mathrm{NS}$ \\
\hline 1,0 & 1,4722 NS & 0,1132 NS & $1,6300 \mathrm{NS}$ \\
\hline 2,0 & 1,4566 NS & $0,1288 \quad N S$ & 1,8556 NS \\
\hline 3,0 & 1,4707 NS & $0,0916 \quad N S$ & $1,6750 \mathrm{NS}$ \\
\hline \multicolumn{4}{|l|}{ Isopentenil adenina } \\
\hline 0 & $1,2719 \mathrm{NS}$ & 0,1987 NS & 2,4571 NS \\
\hline 0,5 & $1,2563 \mathrm{NS}$ & 0,0963 NS & 2,0667 NS \\
\hline 1,0 & $1,5218 \mathrm{NS}$ & 0,0994 NS & 1,7000 NS \\
\hline 2,0 & 1,2811 NS & 0,1504 NS & 2,0125 NS \\
\hline 3,0 & $1,3044 \mathrm{NS}$ & $0,1417 \quad \mathrm{NS}$ & 2,1333 NS \\
\hline \multicolumn{4}{|l|}{ Zeatina } \\
\hline 0 & 1,7766 NS & $0,0727 \quad N S$ & 1,5741 NS \\
\hline 0,5 & 1,7978 NS & 0,0738 NS & 1,5333 NS \\
\hline 1,0 & 1,8032 NS & 0,0571 NS & 1,2633 NS \\
\hline 2,0 & 1,7768 NS & $0,0558 \quad N S$ & $1,3400 \mathrm{NS}$ \\
\hline 3,0 & $1,8353 \mathrm{NS}$ & $0,0736 \quad N S$ & 1,4414 NS \\
\hline
\end{tabular}

NS: não significativo

A inclusão de substâncias reguladoras de crescimento no meio de cultura de embrião foi usada pela primeira vez por Raghavan e Torrey (1963) para substituir as exigências de alta concentração de sacarose ou salina utilizadas no meio de cultura de embriões excisados nos estádios pré-cordiforme e cordiforme. Para $H$. rostrata, a adição ao meio bási- co com $3 \%$ de sacarose de, respectivamente, cinetina $(0,0 ; 0,5 ; 1,0 ; 2,0$ e 3,0 $\left.\mathrm{mg} \mathrm{L}^{-1}\right)$, isopentenil adenina $(0,0 ; 0,5$; 1,$0 ; 2,0$ e $\left.3,0 \mathrm{mg} \mathrm{L}^{-1}\right)$ e zeatina $(0,0 ; 0,5$; 1,$0 ; 2,0$ e $\left.3,0 \mathrm{mg} \mathrm{L}^{-1}\right)$ não afetou estatisticamente a percentagem de plântulas produzidas, massa fresca e o comprimento em relação ao controle (Tabela 1), indicando que o embrião em desen- 
volvimento foi capaz de biossintetizar as citocininas necessárias para seu crescimento.

Os embriões excisados de frutos com pericarpo seco não germinaram em meio com $3 \%$ de sacarose, mostrando a importância do estádio de desenvolvimento dos embriões para o estabelecimento da cultura.

Os resultados obtidos são importantes devido à ineficácia dos métodos de propagação sexuada para $H$. rostrata permitindo a redução de custos na obtenção de matrizes de alta qualidade fitossanitária, na introdução de genótipos nos bancos de germoplasma in vitro e no melhoramento genético dessa espécie.

As mudas produzidas in vitro foram aclimatadas abrindo, gradualmente, os frascos de cultura, cinco dias antes do transplante para vaso, contendo o substrato areia e vermiculita, na proporção $1: 1(\mathrm{v} / \mathrm{v})$ onde desenvolveram-se normalmente. Também, foi verificado, no presente estudo, que a utilização do meio básico com $3 \%$ de sacarose foi efetivo para cultura de embrião de $H$. caribaea, $H$. episcopalis, $H$. psittacorum, H. bihai e $H$. chartacea cv. Sexy Pink.

Pode-se concluir que a adição da sacarose ao meio básico foi essencial para o crescimento e desenvolvimento dos embriões de $H$. rostrata e que a concentração ótima de sacarose que proporcionou o maior número de plântulas foi de 3\%. Em relação aos parâmetros avaliados comprimento, massa fresca e percentagem de plântulas produzidas, a adição de citocininas (cinetina, 2ip, e Zea) ao meio básico não mostrou diferenças significativas entre os tratamentos. Os resultados obtidos foram importantes para a produção de mudas com alta qualidade fitossanitária de $H$. rostrata.

\section{AGRADECIMENTOS}

Os autores agradecem ao Conselho Nacional de Desenvolvimento Científico e Tecnológico pelas bolsas recebidas.

\section{LITERATURA CITADA}

BERRY, F.; KRESS, W.J. Heliconia: an identification guide. 1. ed. Washington: Smithsonian Institution Press. 1991. 334 p.

CASTRO, C.E.F. Helicônia para exportação: aspectos técnicos da produção. Brasília: Embrapa SPI, 1995. 43 p.

CRILEY, R.A. Propagation of tropical cut flowers: Strelitzia, Alpinia and Heliconia. Acta Horticulturae, v.226, p.509-517, 1988.

CRILEY, R.A. Propagation of Zingiberaceae and Heliconiaceae. Revista Brasileira de Horticultura Ornamental, Campinas, v.1, n.1, p.14-21,1995.

CRILEY, R.A.; BROSCHAT. T.K. Heliconia: Botany and Horticulture of a new floral crop. Horticultural Reviews, v.14, p.1-55, 1992.
GÖSSLOVÁ, M.; SVOBODOVÁ, H.; LIPAVSKÁ, H.; ALBRECHTOVÁ, J.; VREUGDENHIL, D. Comparing carbohydrate status during norway spruce seed development and somatic embryo formation. In Vitro Cellular and Developmental Biology - Plant, v.37, p.24-28, 2001.

HU, C.Y.; FERREIRA, A.G. Cultura de Embriões. In: TORRES, A.T.; CALDAS, L.S.; BUSO, J.A. (Eds). Cultura de tecidos e transformação genética de plantas. v.1, Brasília: Embrapa/ SPI, 1998. p.371-393

MURASHIGE, T.; SKOOG, F. A revised medium for rapid growth and bioassays with tobacco tissue cultures. Physiologia Plantarum, v.15, p.473-497, 1962.

NARAYANASWAMI, S.; NORSTOG, K. Plant embryo culture. Botanical Review, v.30, n.4, 1964. RAGHAVAN, V.; TORREY, J.G. Growth and morphogenesis of globular and older embryos of Capsella in culture. American Journal of Botany, v.50, n.6, p.540-551, 1963.

RAPPAPORT, J. In vitro culture of plant embryos and factors controlling their growth. The Botanical Review, v.20, n.4, p.201-225, 1954.

RIETSEMA, J.; SANTINAS, S.; BLAKESLEE, A.F. The effect of sucrose on the growth of Datura stramonium embryos in vitro. American Journal of Botany, v.40, p.538-545, 1953.

SIMÃO, D.G.; SCATENA, V.L. Morphological aspects of the propagation of Heliconia velloziana L. Emygd. (Zingiberales: Heliconiacae). Brazilian Archives of Biology and Technology, v.46, n.1, p.113, 2003.

TREMBLAY, L.; TREMBLAY, F.M. Carbohydrate requirements for the development of black spruce (Picea mariana (Mill.) B.S.P.) and red spruce (P. rubens Sarg) somatic embryos. Plant Cell, Tissue and Organ Culture, v.27, p.95-103, 1991. 